Article

\title{
Innovative Solutions for Reusing Packaging Waste Materials in Humanitarian Logistics
}

\author{
Alberto Regattieri * (D), Mauro Gamberi, Marco Bortolini ${ }^{(1)}$ and Francesco Piana \\ Department of Industrial Engineering, Alma Mater Studiorum-University of Bologna, 40136 Bologna, Italy; \\ mauro.gamberi@unibo.it (M.G.); marco.bortolini3@unibo.it (M.B.); francesco.piana2@unibo.it (F.P.) \\ * Correspondence: alberto.regattieri@unibo.it; Tel.: +39-(0)51-209-3400
}

Received: 18 April 2018; Accepted: 14 May 2018; Published: 16 May 2018

\begin{abstract}
The impact of packaging waste on the environment is becoming unsustainable, which has necessitated a turning point in material recycling and reuse. Such a concept is highly relevant in the humanitarian supply chain due to the huge mass of packaging items that are provided to countries hit by disasters, with these bad conditions making it almost impossible to adopt a rational management of waste streams. The goal of this study is to provide an approach and feasible solutions to reduce the environmental influence of waste produced by packaging and at the same time, to help people affected by disasters. Starting from the analysis of the available materials, several solutions of packaging reuse and recycling are developed and several prototypes are realized and tested in collaboration with the United Nations Humanitarian Response Depots-Lab (UNHRD-Lab), which starts from the basic packaging materials used to supply first-aid to people, including cardboard, pallets, woods, and plastics. This paper addresses the above ideas and presents the design process, results and some quality tests. The experimental evidence encourages future on-field validation in refugee camps.
\end{abstract}

Keywords: packaging material; humanitarian logistics; waste management; material reuse; recycling

\section{Introduction}

Packaging is a big part of the daily materials that people handle and its function, aspect and role are changing due to innovations in the products and processes [1,2]. Packaging materials flow along the supply chain as the products themselves. Furthermore, they also fulfil logistic, marketing and safety requirements [3,4] when containing, storing, handling and shipping goods [5-9]. The literature classifies the following functions of packaging:

- $\quad$ to protect the product quality and properties during shipments [6,10-16];

- $\quad$ to protect the environment from product contamination and hazards [6,17-19];

- to convey information and brand communication attracting customers to choose a particular product [1,20-23]; and

- to reduce the waste of products and losses [24-28].

Among the weaknesses coming from the massive use of packaging materials, their environmental impact is becoming unsustainable due to the raw resource use as well as the amount of $\mathrm{CO}_{2}$ emissions and environmental pollutants caused by their disposal and landfilling. Thus, the market has been encouraged to mitigate these environmental problems by designing packaging with sustainable materials and experimenting with new models and packing methods [29-31]. It is also important to study new strategies and approaches to optimize the treatment of packaging waste to improve global sustainability. 
Sustainability in packaging waste management has to match the most commonly applied definition of sustainable development, which was first proposed by the Brundtland Commission in 1987 [32] as the: '[ . . ] development that meets the needs of the present without compromising the ability of future generations to meet their own needs'. This definition involves addressing three principles of sustainability, which are namely economic, social and environmental [33]. This is strongly connected to the 'triple P model': people (of the developing countries), planet (the eco-systems) and prosperity (equal growth) [34]. From this perspective, packaging waste materials should no longer be considered as garbage but as materials with a potential [35] to be reused or recycled within a secondary lifecycle [36,37].

The introduced environmental problems related to the packaging materials are more evident in certain supply chains, such as the military, space exploration missions [38] and the supply chains associated with the humanitarian field.

This paper addresses the packaging waste management within humanitarian logistics due to the increase in environmental and sustainability issues. When a disaster occurs, a large quantity of humanitarian items arrives in the disaster area to supply the basic needs of the population. After the product are unbundled, the packaging becomes waste immediately and it is collected in the surroundings and/or it is emptied roughly [39], which contributes to a crucial global sustainability problem. Having alternatives to tackle this problem is mandatory. With the aim of addressing this topic, the purpose and innovation of the study is two-fold: (1) to find easy and immediately applicable ways to minimize the environmental impact of the large amount of packaging waste created during emergency aids and (2) to help people affected by disasters, generating useful tools for their daily life from the reuse of the packaging waste.

According to this purpose, the reminder of the paper is organized as follows. Section 2 presents the adopted methodology and provides an overview of common packaging materials available in emergency contexts, while Section 3 presents several prototypes of useful daily products coming from the packaging waste reuse together with their easy-to-assemble procedures. In addition, this section presents some quality tests developed together with the United Nations Humanitarian Response Depots-Lab (UNHRD-Lab), which joined this research. Finally, the conclusions and future research directions are in Section 4.

\section{Method and Materials}

This section presents the adopted methodology and input materials for facing the two-fold problem of treating the packaging waste materials in humanitarian camps and emergency areas and to provide aids to people living in extreme poverty that lack certain basic needs.

\subsection{Method}

Figure 1 proposes the methodology adopted in the present paper. Two study directions appear. On one hand, this involves the analysis of the current standard in humanitarian aids that ships tons of goods to the emergency areas and are responsible for most of the packaging waste materials. On the other hand, this include the investigation and prioritization of the basic needs of people living in such areas.

Concerning the former direction, multiple humanitarian missions were analyzed with the aim of creating lists of shipped materials together with their standard packaging solutions. Such a list is directly correlated to the key streams of packaging waste materials that need to be managed in terms of variety and quantity.

Concerning the latter direction, given the structure and facilities within humanitarian camps, an ordered list of basic needs to supply is provided, which forms the basis for conceiving the original reuses of packaging waste materials.

Starting from the evidence of these two research directions, the generation, design, development, prototyping, lab-test and assessment of multiple solutions of secondary products generated from 
packaging waste materials are conducted. These activities are within the boundaries of this research, while the final field-test and diffusion of the most promising solutions is among the forthcoming activities.

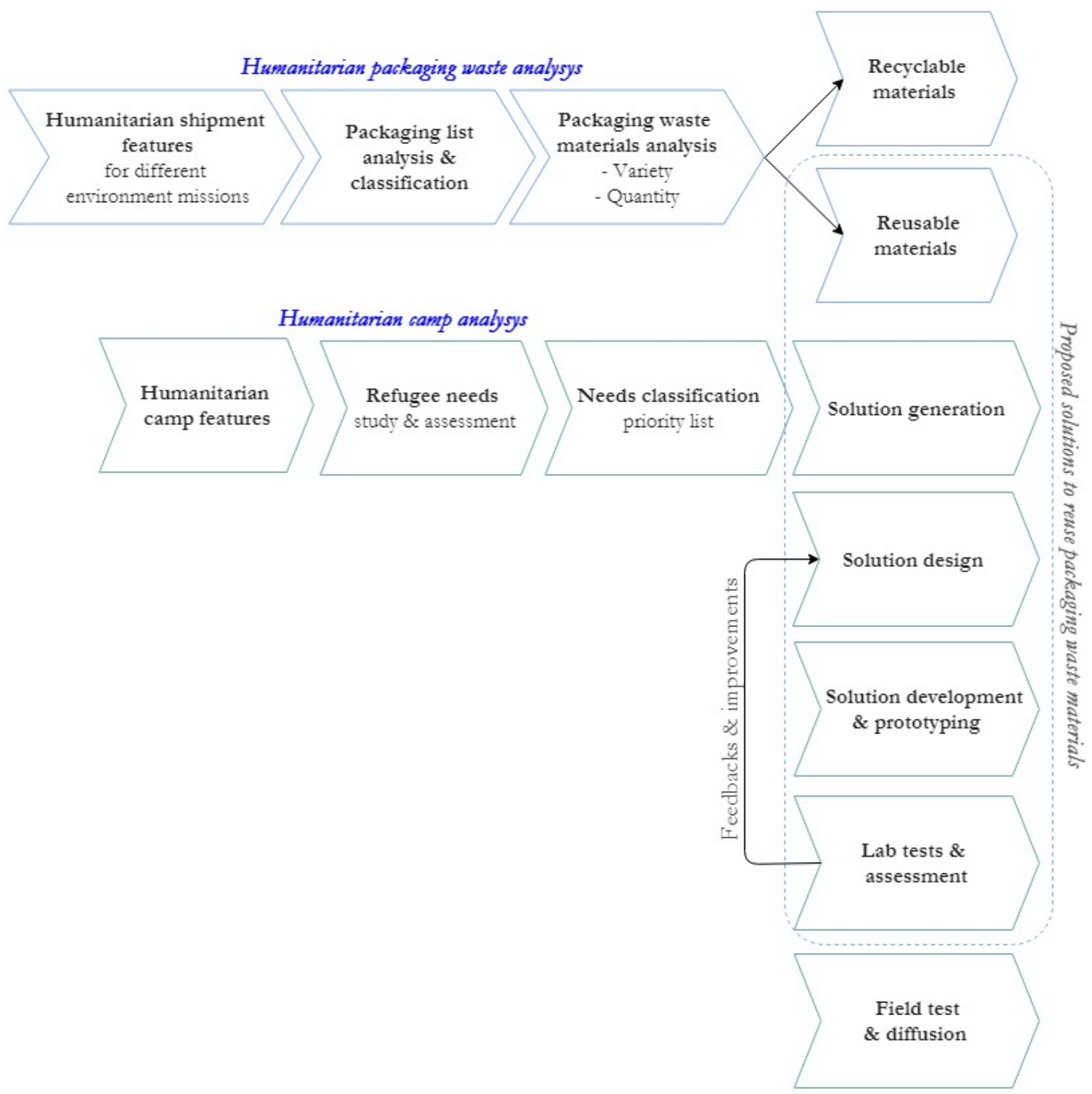

Figure 1. Schematic of the adopted methodology.

\subsection{Input Materials}

According to the first study direction, we evaluated the quantity and variety of the packages usually shipped by the humanitarian organizations to the staging areas and areas close to the catastrophe strike places. In these areas, goods and equipment are stocked, sorted and distributed to people.

In collaboration with the UNHRD-Lab, we conducted a previous study [40] that examined the shipments during 2012 to determine the set of typical humanitarian aids and of most interest, to collect more than 100 packaging lists, which is essentially the list of packaging materials containing products, tools and other aids. Table 1 presents an extract of the analysis that classifies the packaging materials according to their nature for each list and the percentage of the packaging material mass (PM) in the total gross mass (GM) in the last column. 
Table 1. Quantity and types of packaging materials for the selected packing lists [40].

\begin{tabular}{ccccccc}
\hline List Id. & Wooden Box [kg] & Cardboard [kg] & Steel Crate [kg] & Plastic [kg] & Pallet [kg] & PM/GM [\%] \\
\hline 1 & - & 102 & 720 & - & 20 & $10.00 \%$ \\
2 & - & - & 360 & - & 40 & $4.78 \%$ \\
3 & - & - & - & - & 60 & $0.84 \%$ \\
4 & 2320 & 392 & 200 & 1533 & 1302 & $19.21 \%$ \\
5 & 1421 & - & 120 & - & 1230 & $16.91 \%$ \\
6 & - & -640 & - & -2500 & 2200 & $6.88 \%$ \\
7 & - & - & - & - & - & $6.50 \%$ \\
8 & - & - & 1600 & - & $\ldots$ & $\ldots$ \\
$\ldots$ & $\ldots$ & 5328 & & 4066 & 5332 & $11.41 \%$ \\
109 & 200 & & & & & $10.81 \%$ \\
\hline
\end{tabular}

The incidence of the packaging materials is about $10.81 \%$ of the total mass, which is proportional to the relevant costs to ship materials that become waste immediately after the product are unbundled. Local reuse and recycling of such packaging materials is of great interest from both economic and environmental perspectives. To this purpose, some materials are easier to reuse as pallets. Plastic and cardboard are not conceived to have an as-is reuse but they can be reshaped quite easily to create different items.

Because of its large availability and versatility, this study focuses on cardboard from carton boxes as the material waste to reuse. Standard boxes are corrugated fiberboard boxes or regular slotted containers made with double wallboard flute paper with a thickness of 5-7 mm. The thickness and the double wallboard make the cardboard very strong and easy to fold and bend without advanced tools.

\subsection{Refugee Needs}

The needs of people in humanitarian camps and emergency areas are basic as they only require what is important for their survival and daily living. Past studies present the classifications of such needs starting from the micro-scale, such as the needs of the person, through the mid-scale, such as the needs of small groups of people as a family, to the large-scale, such as needs of the community living in the same area [40]. At all the three levels, the solutions are of great importance to guarantee acceptable living conditions, to prevent health risks, to preserve the living areas and to set the foundation for restarting normal living conditions.

This study targets the micro- and mid-scale levels presenting and validating basic prototypes that are useful for the people and family everyday activities, such as moving items, sleeping, sitting, walking, etc. Section 3 details these solutions, which we conceived and tested in partnership with the UNHRD-Lab.

\section{Prototyping from Cardboard Packaging Waste}

Cardboard is one of the most used materials in the packaging of humanitarian items (see Table 1). Double wallboard is a robust material with low weight, which is easy to handle and to cut. Thus, it can be used to obtain different types of equipment even by common people with raw working tools. Such conditions make this packaging waste material a good candidate to investigate.

\subsection{Carton Backpack}

People living in an emergency camp often have to go to common areas that are usually far from their own accommodation to get food or other objects useful for their daily life. They normally do not have effective supports to transport food and other materials. Thus, we began by making a robust backpack from the reused cardboard boxes. Figure 2 shows the design of the proposed backpack. 

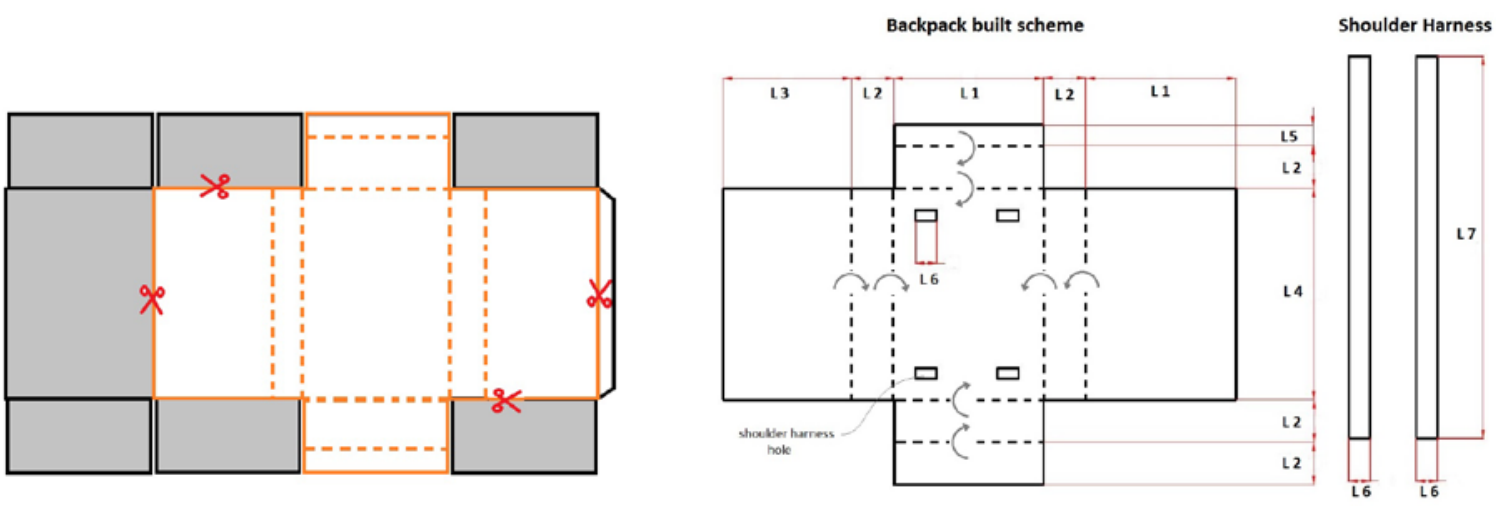

Figure 2. Design of proposed backpack.

Using the proposed design and maintaining the same dimensional relations, it is possible to create a backpack with an appropriate capacity and payload. This backpack is simple to build and it is designed and developed with reproducibility in mind. Its construction does not require complex tools as it only needs a pair of scissors, a simple knife and some packaging tape. To help people who live in humanitarian refugee camps, it is possible to add some packaging tape in the relief packs so that they can make equipment for themselves as presented here. Figure 3 shows the carton backpack that was built using reused packaging from a kitchen set usually shipped by UNHRD in emergency areas.
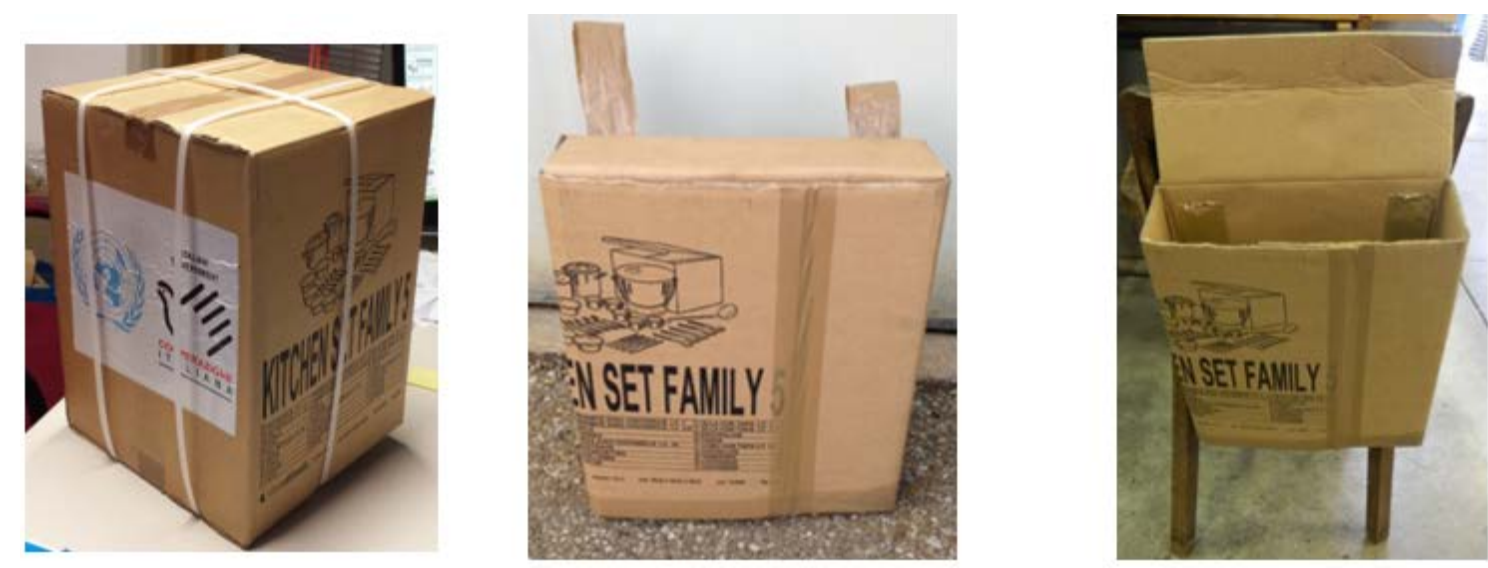

Figure 3. Carton backpack developed and tested using the packaging from a kitchen set provided by UNHRD to the refugees as first aid.

Carton backpack prototypes were tested with regard to payload, shock and damage resistance both in the Laboratory of Industrial Engineering, Bologna University and in the UNHRD-Lab. The results were encouraging. The backpack has a good capacity and an outstanding payload. For example, the backpack in Figure 3 can hold 12 liters and up to $20 \mathrm{~kg}$ of payload for a long time in a dynamic environment with hits. The breaking strength tests show that the carton backpack fails at an average load of $32.4 \mathrm{~kg}$. This is an unexpectedly high result due to the backpack material being reused materials.

\subsection{Carton Cradle}

Many infants live in refugee camps and require specialized equipment, such as cradles. The design of a prototype of carton cradle (Figure 4) was developed, with a simple cradle structure using a joint framework. The dimensions of the cradle could be modified based on the age and size of the infant. 

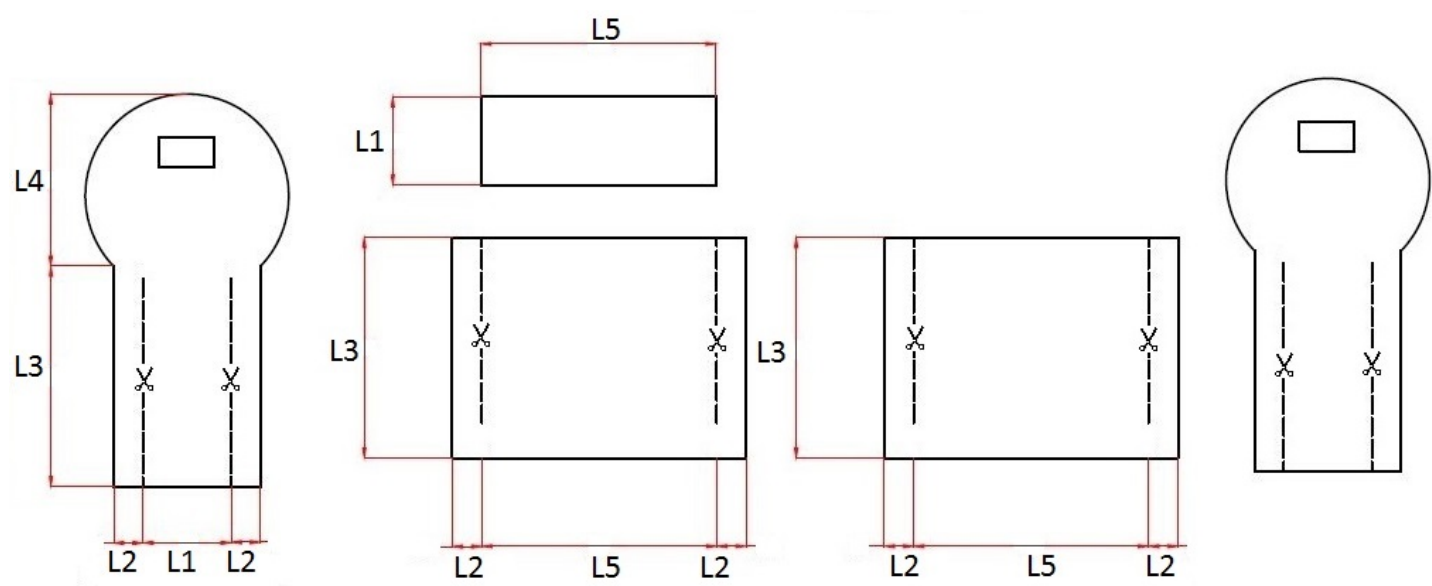

Figure 4. Carton cradle design.

Starting from a common carton box, the two headboards and the two other rectangular sides of the cradle are drawn and cut. After attaching the four sides of the cradle, another rectangular carton was cut and mounted transversely to become a makeshift carton mattress. Figure 5 shows the completed carton cradle.
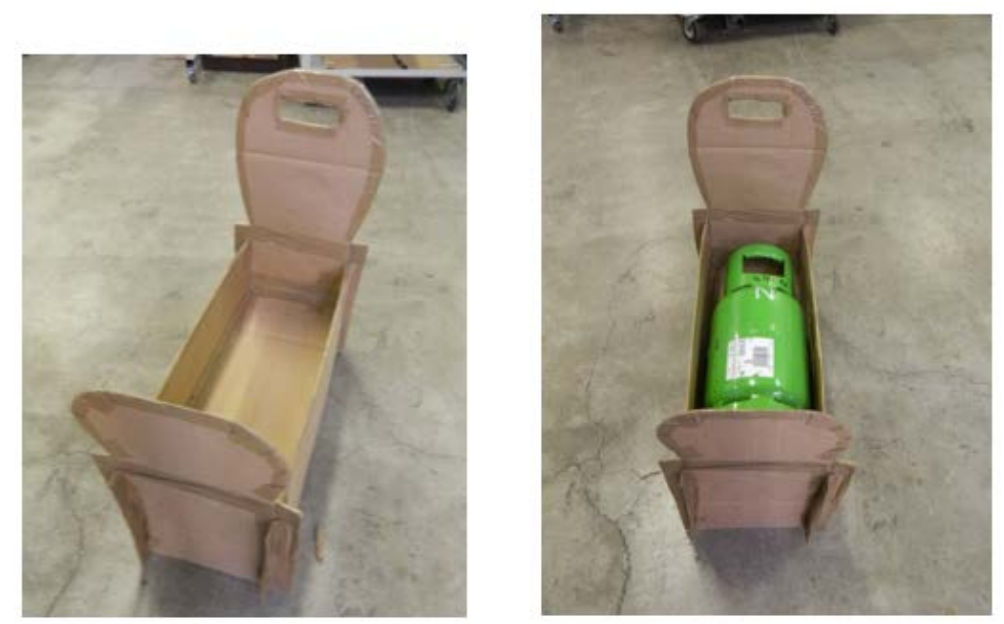

Figure 5. Carton cradle prototype.

The carton cradle prototype is tested with regard to its payload, which showed a resistance up to $15 \mathrm{~kg}$. The breaking strength tests also show that the cradle fails at payloads above $22.6 \mathrm{~kg}$ due to the distortion and failure of the frame. Finally, Figure 4 shows how the frame is designed with minimal complexity using joint connections. Additionally, this type of frame increases the breaking strength of the cradle.

\subsection{Carton Slippers}

The majority of people living in an emergency camp have to walk without any type of shoes. To roughly solve this problem, a pair of very simple slippers were designed using carton boxes. Two versions were developed. The former used one carton-layer with a foot profile drawn onto the carton for sizing. To create the attachment for the top of the foot, a carton strip was drawn and attached to the foot profile. Finally, the slippers were covered with brown packaging tape. Brown packaging tape lends stability to slippers and covers all the shape, making these slippers water-resistant. Figure 6 shows this version. 


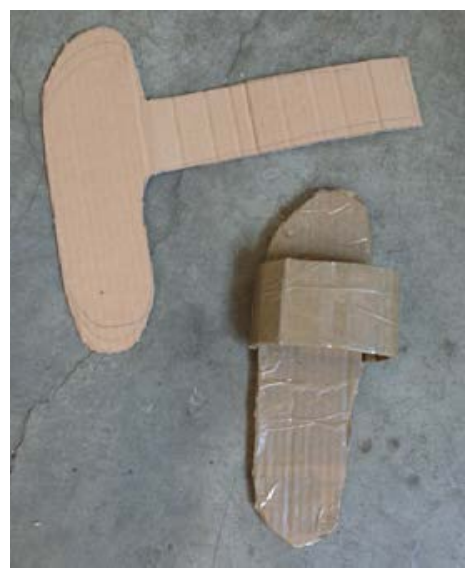

Figure 6. One carton-layer slipper.

The latter version used two carton layers to provide more robustness. Two mirrored foot profiles were designed on the carton. Additionally, in this case, to create the attachment on the top of the foot, a carton strip was drawn. Finally, the slippers were covered with brown tape as before. Figure 7 shows this version.

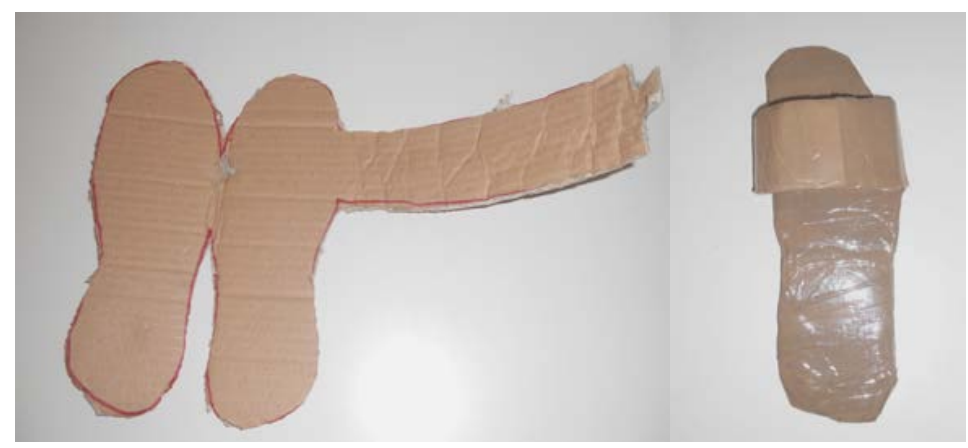

Figure 7. Two carton-layer slipper.

Moreover, to obtain more comfortable slippers, other layers of cardboard can be added to the lower surface of the slipper using brown tape as glue. Cardboard is a good material for this aim as its corrugate structure is able to adapt to the foot and the ground.

\subsection{Carton Stool}

Another useful object to help people in their everyday life coming from carton boxes is a small stool. First, two covers were created using three overlapped circular carton layers. After this, a cylinder of cardboard with the same diameter as the covers provided the vertical height. Finally, a last carton tube prevented the collapse of the stool. Figure 8 shows these components, which are namely the two covers, the cylinder and the tube, together with the assembled device.

The resistance tests show that an $80 \mathrm{~kg}$ person can safely sit and swing on the stool without failure for more than 500 sitting movements. 

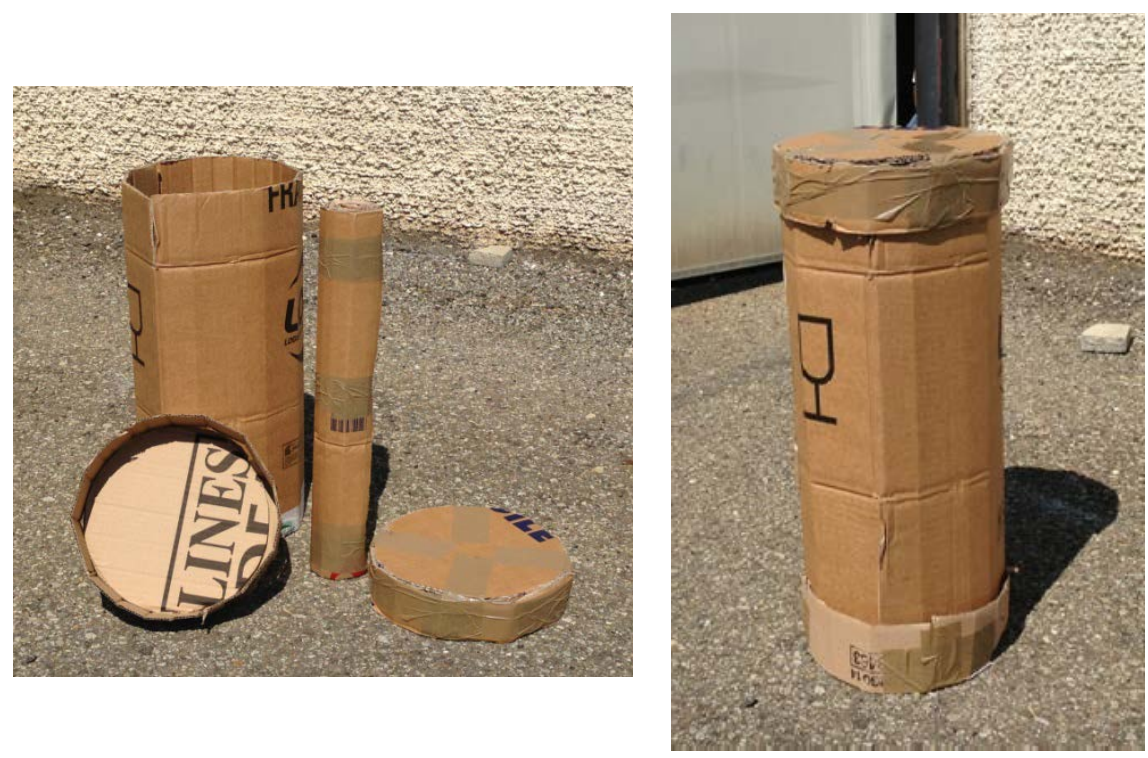

Figure 8. Carton stool, components and final device.

\section{Conclusions and Future Research}

Recently, the importance of packaging management and its increasing functions has become relevant due to innovations and new expectations in packaging materials and methods. According to the multifunctional packaging concept, logistics, marketing and sustainability are the fundamental roles that packaging should consider and integrate. At the same time, the environmental impact of packaging material and waste has risen due to the quantities and quality of such discharged materials. The reuse and recycle of packaging in the supply chain is fundamental, especially in certain supply chains, such as the humanitarian context.

The presented research proposes multiple methods to optimize the treatment of the end-of-life of packaging after their use in emergency fields and after they have fulfilled their primary transportation and stocking function. In collaboration with the United Nations Humanitarian Response Depots-Lab (UNHRD-Lab), we designed and tested several basic equipment for everyday life, including a backpack, cradle, slippers and stool, to aid people affected by disasters and simultaneously reduce the generation of packaging waste. The effectiveness of such devices was tested through basic measures of resistance, obtaining promising preliminary results encouraging future actions.

This study serves as a starting point for future research on the continuous optimization of approaches and methodologies for the reuse of packages in new and different applications in humanitarian supply chains. It could be interesting to test the developed objects in a refugee camp to understand their weaknesses and to attempt to improve them. As the experimental evidence is encouraging, in the near future, several of these prototypes will be sent into the field for testing, with collection of technical and social results.

Author Contributions: M.B. and F.P. revised the background and provided the methodology to be adopted; A.R. collected the input materials; M.G. and F.P. conceived the prototypes; M.B. and F.P. performed the lab-test collecting the results; A.R., M.B. and F.P. wrote the paper.

Acknowledgments: The Authors express a deep sense of gratitude to the United Nations Humanitarian Response Depots-Lab (UNHRD-Lab), Brindisi, Italy for its support and valuable information provided during this study.

Conflicts of Interest: The authors declare no conflict of interest.

\section{References}

1. Domnica, D. Review Concerning the Functions of Packaging. Land Forces Acad. Rev. 2010, 1, 44-49. 
2. Regattieri, A.; Santarelli, G. The Important Role of Packaging in Operations Management. In Operations Management; InTechOpen: London, UK, 2013, ISBN 9789537619343.

3. Twede, D.; Hughes, H. Packaging for logistical support. In Proceedings of the AIAA 2nd Space Logistics Symposium, Costa Mesa, CA, USA, 3-5 October 1988; American Institute of Aeronautics and Astronautics Inc., AIAA: Costa Mesa, CA, USA, 1988; pp. 58-64.

4. Saghir, M. The concept of Packaging Logistics. In Proceedings of the Second World Conference on POM and 15th Annual POM Conference, Cancun, Mexico, 30 April-3 May 2004; pp. 1-31.

5. Beckeman, A.; Lu, M.; Lu, C. Past and Present Roles of Packages in Logistics and towards the Future. In Logistics Research Nwork 2007 Conference Proceedings; The Chartered Institute of Logistics and Transport: Corby, UK, 2007.

6. Hellström, D.; Saghir, M. Packaging and logistics interactions in retail supply chains. Packag. Technol. Sci. 2007, 20, 197-216. [CrossRef]

7. Regattieri, A.; Santarelli, G.; Gamberi, M.; Mora, C. A New Paradigm for Packaging Design in Web-Based Commerce Regular Paper. Int. J. Eng. Bus. Manag. 2014, 6, 14. [CrossRef]

8. Twede, D. The cask age: The technology and history of wooden barrels. Packag. Technol. Sci. 2005, 18, 253-264. [CrossRef]

9. Yoshida, A.; Taniguchi, J.; Murata, K.; Kada, M.; Yamamoto, Y.; Takagi, Y.; Notomi, T.; Fujita, A. A study on package stacking process for Package-on-Package (PoP). In Proceedings of the 56th Electronic Components and Technology Conference, San Diego, CA, USA, 30 May-2 June 2006; pp. 825-830. [CrossRef]

10. Dominic, C. Integrating packaging suppliers into the supply/demand chain. Packag. Technol. Sci. 2005, 18, 151-160. [CrossRef]

11. Klevås, J. Organization of packaging resources at a product-developing company. Int. J. Phys. Distrib. Logist. Manag. 2005, 35, 116-131. [CrossRef]

12. Olander-Roese, M.; Nilsson, F. Competitive advantage through packaging design? Propositions for supply chain effectiveness and efficiency. In Proceedings of the 17th International Conference on Engineering Design (ICED 09), Palo Alto, CA, USA, 24-27 August 2009; pp. 279-290.

13. Tardiff, M.; Riley, J. Delivery and Dispersion of Humanitarian Aid. In Proceedings of the 23rd AIAA Aerodynamic Decelerator Systems Technology Conference, Daytona Beach, FL, USA, 2 April 2015; American Institute of Aeronautics and Astronautics: Reston, VA, USA, 2015; p. 2018.

14. Djenane, D.; Roncalés, P. Carbon Monoxide in Meat and Fish Packaging: Advantages and Limits. Foods 2018, 7, 12. [CrossRef] [PubMed]

15. Kerry, J.P.; O'Grady, M.N.; Hogan, S.A. Past, current and potential utilisation of active and intelligent packaging systems for meat and muscle-based products: A review. Meat Sci. 2006, 74, 113-130. [CrossRef] [PubMed]

16. Biji, K.B.; Ravishankar, C.N.; Mohan, C.O.; Srinivasa Gopal, T.K. Smart packaging systems for food applications: A review. J. Food Sci. Technol. 2015, 52, 6125-6135. [CrossRef] [PubMed]

17. Klevas, J. Design for Packaging Logistics. Int. Des. Conf. 2006, 269-276.

18. Shea, O. Packaging pointers for the best protection. Eval. Eng. 1996, 35, 2018.

19. Szymonik, A. Packaging in Logistics; working paper; Technical University of Lodz: Lodz, Poland, 2016.

20. Rundh, B. The Role of Packaging within Marketing and Value Creation. Br. Food J. 2016, 118, $2491-2511$. [CrossRef]

21. Underwood, R.L. The Communicative Power of Product Packaging: Creating Brand Identity via Lived and Mediated Experience. J. Mark. Theory Pract. 2003, 11, 62-76. [CrossRef]

22. Rod, S. Packaging as a Retail Marketing Tool. Int. J. Phys. Distrib. Logist. Manag. 1990, 20, 29-30. [CrossRef]

23. Dominic, C. Packaging logistics performance and how to evaluate the packaging performance by applying the tool packaperforma. In Proceedings of the 17th IAPRI World Conference on Packaging, Tianjin, China, 12-15 October 2010; pp. 245-250.

24. Regattieri, A.; Piana, F.; Bortolini, M.; Gamberi, M.; Ferrari, E. Innovative portable solar cooker using the packaging waste of humanitarian supplies. Renew. Sustain. Energy Rev. 2016, 57, 319-326. [CrossRef]

25. Accorsi, R.; Versari, L.; Manzini, R. Glass vs. plastic: Life cycle assessment of extra-virgin olive oil bottles across global supply chains. Sustainability 2015, 7, 2818-2840. [CrossRef]

26. Eschke, K.-R. Packaging reduction by design. Packag. Technol. Sci. 1995, 8, 139-147. [CrossRef] 
27. Davis, G.; Song, J.H. Biodegradable packaging based on raw materials from crops and their impact on waste management. Ind. Crops Prod. 2006, 23, 147-161. [CrossRef]

28. Chen, J.; Zhang, Y.L.; Sun, J. An overview of the reducing principle of design of corrugated box used in goods packaging. Procedia Environ. Sci. 2011, 10, 992-998. [CrossRef]

29. Samson, R.; Camenforte, R.A.; Duldulao, L. Robust packaging solutions through innovative designs in clip-QFN. In Proceedings of the 2015 IEEE 17th Electronics Packaging and Technology Conference (EPTC), Singapore, 2-4 December 2015; IEEE: Piscataway, NJ, USA, 2015; pp. 1-3.

30. Bogóné-Tóth, Z.; Lakner, Z.; Hajdu, I.; Fehér, O. Life cycle analysis as a tool of complex evaluation of food packaging systems. In Challenges for Technology Innovation: An Agenda for the Future; CRC Press, Taylor \& Francis Group: Boca Raton, FL, USA, 2017; pp. 249-256.

31. Espinoza-Orias, N.; Batley, S.; Grassi-Hertz, S.; Halvorson, S.; Schenker, U.; Detrois, C. Eco-design shapes product innovation and development. Food Sci. Technol. 2016, 30, 26-28.

32. United Nations. Report of the World Commission on Environment and Development; UN: New York, NY, USA, 1978.

33. Ferrão, P.; Ribeiro, P.; Rodrigues, J.; Marques, A.; Preto, M.; Amaral, M.; Domingos, T.; Lopes, A.; Costa, E.I. Environmental, economic and social costs and benefits of a packaging waste management system: A Portuguese case study. Resour. Conserv. Recycl. 2014, 85, 67-78. [CrossRef]

34. Wever, R.; Vogtlander, J. Handbook of Ethics, Values, and Technological Design; van den Hoven, J., Vermaas, P.E., van de Poel, I., Eds.; Springer: Dordrecht, The Netherlands, 2017, ISBN 978-94-007-6994-6.

35. Müller, G.; Hanecker, E.; Blasius, K.; Seidemann, C.; Tempel, L.; Sadocco, P.; Pozo, B.F.; Boulougouris, G.; Lozo, B.; Jamnicki, S.; et al. Effect of high-pressure food processing on the mass transfer properties of selected packaging materials. Packag. Technol. Sci. 2012, 23, 253-266. [CrossRef]

36. Zhang, J. Study on the value chain construct of the cyclic utilization of waste packages. In Proceedings of the International Conference on Management and Service Science (MASS'09), Wuhan, China, 20-22 September 2009. [CrossRef]

37. Mollenkopf, D.; Closs, D.; Twede, D.; Lee, S.; Burgess, G. Assessing the Viability of Reusable Packaging: A Relative Cost Approach. J. Bus. Logist. 2005, 26, 169-197. [CrossRef]

38. Ewert, M.K.; Broyan, J.L. Mission Benefits Analysis of Logistics Reduction Technologies. In Proceedings of the 43rd International Conference on Environmental Systems (ICES), Vail, CO, USA, 14-18 July 2013; American Institute of Aeronautics and Astronautics Inc., AIAA: Reston, VA, USA, 2013; pp. 1-9.

39. Kilbride, A.; Kramer, A.; Preneta, N. Piloting ecological sanitation (EcoSan) in the emergency context of Port-au-Prince, Haiti, after the 2010 earthquake. In Proceedings of the 36th Water, Engineering and Development Centre International Conference, Nakuru, Kenya, 1-5 July 2013; pp. 1-6.

40. Regattieri, A.; Santarelli, G.; Piana, F.; Gamberi, M. Classification of Technical Requirements and the Means of Addressing the Problem of Waste Management in a Refugee Camp. In Humanitarian Logistics and Sustainability; Klumpp, M., Sander, L., Regattieri, A., Eds.; Springer International Publishing: Cham (ZG), Switzerland, 2015; pp. 169-192, ISBN 3319154540.

(C) 2018 by the authors. Licensee MDPI, Basel, Switzerland. This article is an open access article distributed under the terms and conditions of the Creative Commons Attribution (CC BY) license (http://creativecommons.org/licenses/by/4.0/). 